\title{
A dimensão afetiva e as competências socioemocionais na formação do enfermeiro: um estudo sociopoético
}

\author{
The affective dimension and socioemotional competences in the training of nurses: a sociopetic stu- \\ dy
}

\section{La dimensión afectiva y las competencias socioemocionales en la formación de enfermeras: un estu- dio sociopético}

\section{Thainá Oliveira Lima ${ }^{1 *}$, Claudia Mara de Melo Tavares²}

Como citar esse artigo. Lima, T.O; Tavares, C.M.M. A dimensão afetiva e as competências socioemocionais na formação do enfermeiro: um estudo sociopoético. Revista Pró-UniverSUS. 2021 Jan./Jun.; 12 (1): 73-76.

\section{Resumo}

Originado do projeto de Doutorado em Ciências do Cuidado em Saúde da Universidade Federal Fluminense. Objetivo geral: Compreender o desenvolvimento da dimensão afetiva e das competências socioemocionais através das experimentações estéticas da sociopoética. Objetivos específicos: Discutir com os graduandos de enfermagem suas vivências socioemocionais durante o curso de graduação em enfermagem, considerando o ensino teórico-prático e o estágio curricular, com enfoque na dimensão afetiva e nas competências socioemocionais; Refletir acerca do potencial de inovação da sociopoética no campo das emoções; Propor medidas para valorização da abordagem socioemocional na formação do enfermeiro; Refletir acerca das experiências emocionais dos alunos durante o período de pandemia do Coronavírus. Método: estudo sociopoético, cujos sujeitos são os alunos do $6^{\circ}$ período do curso de enfermagem da Universidade Federal Fluminense. Produção dos dados realizada por meio do dispositivo do grupo - pesquisador através das experimentações estéticas da sociopoética. Os dados foram tratados mediante o estudo filosófico sociopoético. Resultados preliminaries: três categorias emergiram dos dados: "O ato cognoscente no processo de formação", "A necessidade de ser um enfermeiro que irá marcar/iluminar a vida do outro", "As dificuldades socioafetivas dos professores de graduação no ensino remoto/virtual". O dado mais evidente e oposto ao que se pretendia na dinâmica proposta, foi a falta de intermediação ou mesmo alusão aos vídeos apresentados (música e poesia). Os alunos apenas responderam ao tema gerador através de suas produções.

Palavras-chave: Educação em Enfermagem; Estudantes de Enfermagem; Emoções.

\begin{abstract}
Originated from the Doctoral project in Health Care Sciences at Universidade Federal Fluminense. General objective: To understand the development of the affective dimension and socioemotional competences through the aesthetic experiments of sociopoetics. Specific objectives: Discuss with nursing students their socio-emotional experiences during the undergraduate nursing course, considering the theoretical-practical teaching and the curricular internship, with a focus on the affective dimension and socio-emotional competences; Reflect on the innovation potential of sociopoetics in the field of emotions; Propose measures to enhance the socio-emotional approach in the training of nurses; Reflect on students' emotional experiences during the Coronavirus pandemic period. Method: sociopoetic study, whose subjects are students of the 6th period of the nursing course at Universidade Federal Fluminense. Data production performed using the group device - researcher through the aesthetic experiments of sociopoetics. The data were treated by means of a socio-poetic philosophical study. Preliminary results: three categories emerged from the data: "The cognitive act in the training process", " The need to be a nurse who will mark / illuminate the lives of others' ', 'The socio-affective difficulties of undergraduate teachers in the remote / virtual teaching ". The most evident fact and opposite to what was intended in the proposed dynamic, was the lack of intermediation or even allusion to the videos presented (music and poem). The students only responded to the generator theme through their productions.
\end{abstract}

Keywords: Nursing Education; Nursing students; Emotions

${ }^{1}$ Enfermeira, Doutoranda do Programa Acadêmico de Ciências do Cuidado em Sáude da Universidade Federal Fluminense, Niterói, Rio de Janeiro, Brasil, País. E-mail: oliveira. thina@hotmail.com ORCID: https://orcid.org/0000-0002-9900-4591

${ }^{2}$ Enfermeira, Professora Titular da Escola de Enfermagem Aurora de Afonso Costa da Universidade Federal Fluminense - Doutora em Enfermagem - Niterói, Rio de Janeiro, Brasil. E-mail: oliveira.thina@hotmail.com ORCID: https://orcid.org/0000-0002-8416-6272 


\section{Resumen}

Procedente del proyecto de doctorado en Ciencias de la Salud de la Universidade Federal Fluminense. Objetivo general: Comprender el desarrollo de la dimensión afectiva y las competencias socioemocionales a través de los experimentos estéticos de la sociopoética. Objetivos específicos: Discutir con los estudiantes de enfermería sus vivencias socioemocionales durante el curso de licenciatura en enfermería, considerando la docencia teórico-práctica y el internado curricular, con enfoque en la dimensión afectiva y competencias socioemocionales; Reflexionar sobre el potencial de innovación de la sociopoética en el campo de las emociones; Proponer medidas para valorar el enfoque socioemocional en la formación de enfermeras; Reflexione sobre las experiencias emocionales de los estudiantes durante el período de la pandemia del coronavirus. Método: estudio sociopoético, cuyos sujetos son estudiantes del sexto período de la carrera de enfermería de la Universidade Federal Fluminense. Producción de datos realizada utilizando el dispositivo grupal - investigador a través de los experimentos estéticos de la sociopoética. Los datos fueron tratados mediante un estudio filosófico socio-poético. Resultados preliminares: de los datos surgieron tres categorías: 'El acto cognitivo en el proceso de formación' ',' La necesidad de ser una enfermera que marcará / iluminará la vida de los demás ',' Las dificultades socio-afectivas de la docentes en la enseñanza remota / virtual '. El hecho más evidente y contrario a lo que se pretendía en la dinámica propuesta, fue la falta de intermediación o incluso alusión a los videos presentados (música y poema). Los estudiantes solo respondieron al tema generador a través de sus producciones. Palabras clave: Educación en enfermería; Estudiantes de enfermería; Emociones.

\section{Introdução}

As emoções estão presentes em todos os espaços e organizações, e as ações ocorrem apartir das emoções que sentimentos, sem elas nenhum ação ocorrerá, elas são responsáveis por moldar as relações e os ambientes, são integrantes da vida diária e das necessidades de adaptação como ocorre na dimensão da formação dos estudantes de enfermagem, que muitas vezes precisam aprender a reconhecer suas emoções e as dos outros ${ }^{1}$.

Em diversas pesquisas encontradas sobre as emoções e percepções dos graduandos de enfermagem sobre sua formação, destaca-se que a mesma ainda permanece centrada em aspectos técnicos-científicos e direcionada aqueles que serão cuidados, sem analisar o universo das emoções daqueles que estão a se formar, pois a trajetória de formação é atravessada por diversas experiências que envolvem os sentimentos e emoções dos estudantes ${ }^{2}$. Os estudantes têm necessidade de aprender como gerenciar seu processo formativo bem como seus processos emocionais (internos), para melhor desempenho durante a formação ${ }^{3}$.

O grande desafio da atualidade na formação em saúde e em especial na formação do enfermeiro é conciliar o desenvolvimento técnico-científico a consciência do desenvolvimento da dimensão humana e emocional $1^{4}$. O processo educativo pode ser concebido de diversas formas, nele está presente a dimensão técnica, cognitiva, emocional, política, cultural entre outras. O que é necessário compreender é que o processo de formação não deve ser uma justaposição dessas dimensões, mas um processo integrado onde as diversas dimensões são trabalhadas implicando no crescimento pessoal e profissional do enfermeiro, principalmente no desenvolvimento de habilidades e atitudes ${ }^{5}$.

A noção de competência surge quando se vai além do conhecimento adquirido academicamente, quando o conhecimento é concebido a partir das experiências do indivíduo, seja no universo de formação, do trabalho ou ao longo da vida, diante da reflexão desses universos ${ }^{6}$.

Em geral, essas competências socioemocionais podem ser divididas em cinco: conscienciosidade (persistência, resiliência e outras); abertura a novas experiências (presente em comportamentos de curiosidade, criatividade, não ter medo de errar, entre outros.); amabilidade (presente em cooperação, por exemplo); estabilidade emocional (na capacidade de autocontrole e outras) e extroversão (como sociabilidade $)^{7}$.

Vale destacar a importância do desenvolvimento das competências socioemocionais durante a formação acadêmica, pois o cuidado será marcado por pelo comportamento e atitudes daqueles que cuidam ${ }^{8}$.

Com essa perspectiva, a formação passa a ter outros significados que não aqueles atribuídos pelas dimensões técnicas-científicas, pois é preciso recuperar um ser humano que seja capaz de voltar a cultivar suas emoções, seus instintos e sua dimensão afetiva ${ }^{9}$.

Objetivo geral: Compreender o desenvolvimento da dimensão afetiva e das competências socioemocionais através das experimentações estéticas da sociopoética.

Objetivos específicos: 1- Discutir com os graduandos de enfermagem suas vivências socioemocionais durante o curso de graduação em enfermagem, considerando o ensino teórico-prático e o estágio curricular, com enfoque na dimensão afetiva e nas competências socioemocionais; 2- Refletir acerca do potencial de inovação da sociopoética no campo das emoções; 3- Propor medidas para valorização da abordagem socioemocional na formação do enfermeiro; 4- Refletir acerca das experiências emocionais dos alunos durante o período de pandemia do Coronavírus.

\section{Metodologia}

Trata-se de estudo qualitativo, descritivo, com abordagem sociopoética. A escolha pela pesquisa 
qualitativa decorre do desejo de investigar a subjetividade de cada um dos sujeitos envolvidos na pesquisa.

A pesquisa qualitativa trabalha significados, motivos, aspirações, crenças, valores e atitudes, o que corresponde a um espaço mais profundo das relações, dos processos e dos fenômenos que não podem ser reduzidos à quantificação ou operacionalização de variáveis ${ }^{10}$.

Sendo assim foi utilizada a abordagem sociopoética que trabalha com a valorização de estratégias e técnicas que dão lugar a criatividade, ao imaginário, ao trabalho inconsciente, a intuição e ao saber e expressão dos participantes, com objetivo de compreender melhor a realidade ${ }^{11}$.

O principal dispositivo e método utilizado pela sociopoética é o do grupo-pesquisador, nele ocorre as experimentações estéticas, os pesquisadores passam a ser facilitadores e os participantes protagonistas na condução da pesquisa (na produção, análise e validação dos dados), nestas experimentações é acordado um tema-gerador que será trabalhado artisticamente pelo grupo $^{12}$.

A pesquisa teve como cenário a Escola de Enfermagem Aurora de Afonso Costa da Universidade Federal Fluminense. Os participantes foram os alunos do $6^{\circ}$ período do curso de graduação em enfermagem. Como critério de inclusão participaram os alunos que cursavam a disciplina de saúde mental, devido ao trabalho integrado de pesquisa e estágio a docência na disciplina, alunos regularmente matriculados, de ambos os sexos e maiores de 18 anos. Como critérios de exclusão, não participaram da pesquisa alunos dos demais períodos da graduação, bem como alunos ouvintes.

O tratamento e a análise dos dados foram feitos a partir das falas, expressões verbais e artísticas do grupo pesquisador. Os dados foram analisados conforme os estudos filosóficos da sociopoética e interpretados à luz das perspectivas dos afetos de Baruch de Spinoza e Gilles Deleuze. ${ }^{13,14}$

A pesquisa foi submetida à apreciação do Comitê de Ética em Pesquisa da Universidade Federal Fluminense - UFF, respeitando os princípios da Resolução 466/12, a qual normatiza a realização de pesquisas envolvendo seres humanos, sendo aprovada sob $\mathrm{n}^{\circ}$ do parecer: 3.659 .979 .

\section{Resultados Premilinares}

De início foi organizada uma atividade com o grupo- pesquisador que ocorreu de forma on-line/remota devido a pandemia do coronavírus, a atividade propôs a reflexão a partir do tema gerador: ' $E$ se eu pudesse ser o enfermeiro que eu quero ser?" "Como eu seria?" "'O que eu faria?" com base na música "De toda cor" do autor Renato Luciano e no poema de Clarice Lispector
"E se eu fosse eu", também foi pedido aos alunos que desenvolvessem produções criativa para expressão da temática.

A partir da análise prévia dos dados surgiram três categorias: " $\mathrm{O}$ ato cognoscente no processo de formação", "A necessidade de ser um enfermeiro que irá marcar/iluminar a vida do outro", "'As dificuldades socioafetivas dos professores de graduação no ensino remoto/virtual". Vale ressaltar que a turma participante da pesquisa já vinha sendo sensibilizada por práticas criativas de ensino-aprendizagem, visto que a turma cursava no momento a disciplina de saúde mental.

$\mathrm{O}$ achado de maior destaque foi detectar que os alunos não fizeramnenhum tipo de correlação ou conexão com a música ou poema proposto para a atividade, foi perceptível o oposto do que se pretendia na dinâmica proposta, os alunos não fizeram intermediação ou mesmo alusão aos vídeos apresentados, apenas responderam ao tema gerador através de suas produções. O que leva ao questionamento se o espaço virtual interfere na capacidade do sujeito de se afetar?

\section{Referências}

1. Vilelas JMS, Diogo PM.J. Emotional labor in nursing praxis. Revista Gaúcha de Enfermagem. 2014; 35(3):145-149.

2. Perbone JG, Carvalho EC. Sentimentos do estudante de enfermagem em seu primeiro contato com pacientes. Revista Brasileira de Enfermagem. 2011; 64, (2):343-347.

3. Smith P. The Emotional Labour of Nursing Revisited: Can Nurses Still Care? (2. ${ }^{a}$ Edição). Hampshire: Palgrave Macmillan. Terry, L. \& Carroll, J. Dealing with death: first encouters for first-year nursing students. British Journal of Nursing. 2008; 17 (12): 760-764.

4. Berger MVB. Educação transpessoal: integrando o saber ao ser no processo educativo. Tese (Doutorado em Educação) - Universidade Estadual de Campinas, São Paulo. 2001. Disponível em: <http://repositorio.unicamp. br/jspui/bitstream/REPOSIP/253658/1/Berger_MariaVirginiaBernardi D. pdf $>$. Acesso em: 19 de maio de 2021.

5. Mizukami MGN. Ensino: as abordagens do processo. São Paulo: EPU, 1986.

6. Souza JJGC, Cavalcanti ATA, Monteiro EMLM, Silva MI. Como será o amanhã? Responda quem puder! Perspectivas de enfermeirandos quanto ao seu futuro profissional. Revista Braileira de Enfermagem. 2003; 56(4): 453458 .

7. Damásio A. E o cérebro criou o Homem. São Paulo: Companhia das Letras, 2011. (Original em inglês: Self Comes to Mind: Constructing the Conscious Brain. New York: Pantheon, 2010).

8. Lopes RCC, Azeredo ZAS, Rodrigues RMC. Competências relacionais: necessidades sentidas pelos estudantes de enfermagem. Revista Latino Americana de Enfermagem. 2012; Nov/Dec; 20 (6): 1-10.

9. Lima TO. A premência do desenvolvimento de competências socioemocionais na formação do enfermeiro: estudo sociopoético. Dissertação de Mestrado, Universidade Federal Fluminense, Rio de Janeiro, Brasil, 2017.

10. Minayo MCS. O desafio do conhecimento: pesquisa qualitativa em saúde. São Paulo: Hucitec, 2004; 8: 269.

11. Nery MP, Costa LF. Desafios para uma epistemologia da pesquisa com grupos. Aletheia. 2007; (25): 123-138.

12 Tavares CMM. Como desenvolver experimentações estéticas para produção de dados na pesquisa sociopoética e abordagens afins? Revista 
Lima \& Tavares, 2021.

Pró-UniverSUS. 2016 Jul/Dez.; 07 (3): 26-31.

13 Spinoza B. Ética. Belo Horizonte: Autêntica, 2009.

14 Deleuze G. Lógica do sentido. Trad. Luiz Roberto Salinas Fortes. São

Paulo: Perspectiva, 1982. 